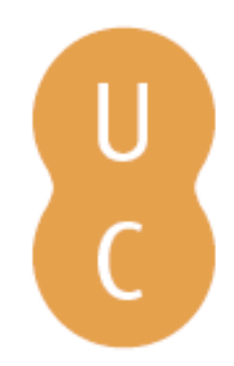

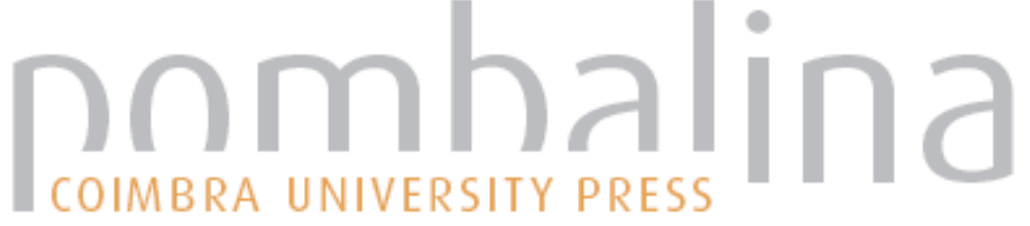

\section{A ratio studiorum e a educação da Europa: Atenas, Roma e Jerusalém}

Autor(es): $\quad$ Miranda, Margarida

Publicado por: Imprensa da Universidade de Coimbra

URL

persistente:

URI:http://hdl.handle.net/10316.2/38964

DOI:

DOI:http://dx.doi.org/10.14195/978-989-26-0395-7_18

Accessed : $\quad$ 26-Apr-2023 04:34:49

A navegação consulta e descarregamento dos títulos inseridos nas Bibliotecas Digitais UC Digitalis, UC Pombalina e UC Impactum, pressupõem a aceitação plena e sem reservas dos Termos e Condições de Uso destas Bibliotecas Digitais, disponíveis em https://digitalis.uc.pt/pt-pt/termos.

Conforme exposto nos referidos Termos e Condições de Uso, o descarregamento de títulos de acesso restrito requer uma licença válida de autorização devendo o utilizador aceder ao(s) documento(s) a partir de um endereço de IP da instituição detentora da supramencionada licença.

Ao utilizador é apenas permitido o descarregamento para uso pessoal, pelo que o emprego do(s) título(s) descarregado(s) para outro fim, designadamente comercial, carece de autorização do respetivo autor ou editor da obra.

Na medida em que todas as obras da UC Digitalis se encontram protegidas pelo Código do Direito de Autor e Direitos Conexos e demais legislação aplicável, toda a cópia, parcial ou total, deste documento, nos casos em que é legalmente admitida, deverá conter ou fazer-se acompanhar por este aviso. 
Nair de Nazaré Castro Soares

Santiago López Moreda

Coordenação

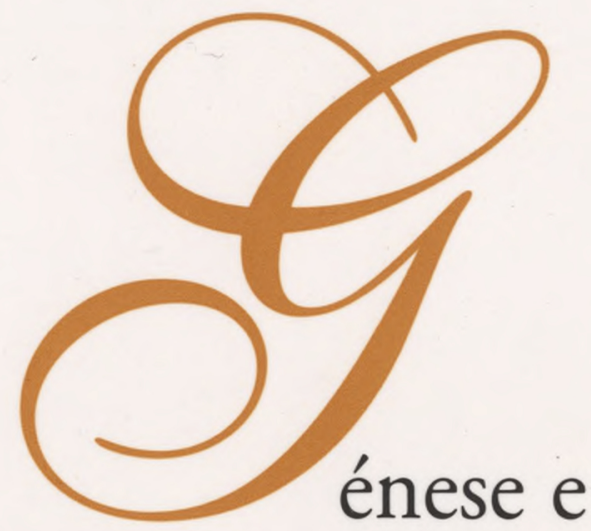

Consolidação da Ideia de Europa

Vol. IV

Idade Média e Renascimento

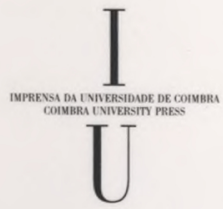

- COIMBra 2009 


\title{
A RATIO STUDIORUM E A EDUCAÇÃO DA EUROPA. ATENAS, ROMA E JERUSALÉM ${ }^{1}$
}

\author{
MARGARIDA MIRANDA \\ Universidade de Coimbra
}

\author{
INTRODUÇÃO: ATENAS, ROMA E JERUSALÉM
}

Após a elaboração de uma longa História das Ideias Políticas ${ }^{2}$, desde a Antiguidade até aos nossos dias, e à luz do que esse longo trabalho the ensinou, o seu autor, Philippe Nemo, ensaiou também uma síntese daquilo que pensa ser a estrutura da morfogénese cultural do Ocidente: Qu'est-ce qu'est l'Occident (P.U.F.), 2004. O livro foi aceite com grande interesse por todo o Ocidente. Foi merecedor de prémios ensaísticos e traduzido para diversas línguas modernas (português, italiano, alemão e inglês).

Sem prejuízo de toda a complexidade própria desta unidade cultural chamada Europa, Philippe Nemo salienta cinco acontecimentos essenciais, fundadores do Ocidente cultural ${ }^{3}$. Um de origem grega, a que chama invenção da Cidade e do primado da lei, invenção da liberdade, invenção da ciência e da escola. O governo pela lei é invenção grega, propiciada pelo aparecimento da polis, pelo uso renovado da escrita e pela valorização da palavra e da razão.

${ }^{1}$ Este estudo desenvolve um outro estudo publicado sob o título "Humanismo Jesuítico e identidade da Europa. Uma "Comunidade Pedagógica Europeia"” Humanitas LIII (2001) 83-111, já então elaborado no âmbito do Projecto de Investigação do Centro de Estudos Clássicos e Humanísticos: «Génese e Consolidação da Ideia de Europa. Raízes de Identidade».

${ }^{2}$ Philippe Nemo, Histoire des idées politiques dans l'Antiquité et au Moyen Âge, Paris, P.U.F., 1998; Histoire des idées politiques aux temps modernes et contemporains, Paris, P.U.F., 2002.

${ }^{3}$ Da numerosa bibliografia do autor sobre esta matéria, salientarei "Athènes, Rome, Jérusalem: trois piliers de l'identité européenne" in Philippe Nemo (org.), L'Union européenne et les États-nations, ESCP, 1988. 
$O$ resultado desse conjunto de circunstâncias, a que devemos acrescentar ainda a igualdade perante a lei, é a noção de cidadão, com o que esta implicou de inovação, do ponto de vista do direito e da razão humana.

Um outro factor, de origem romana, prende-se com a invenção do direito e constitui uma das fontes essenciais do humanismo ocidental e da própria noção de pessoa. O carácter multiétnico do Estado romano fê-lo dar um passo gigantesco na criação de um direito universal (sobre a natureza humana universal, cognoscível pela razão) e simultaneamente na criação do direito privado, sinal de que a concepção de homem e de pessoa humana mudara radicalmente.

Outro factor do Ocidente é designado por Philippe Nemo como revolução ética e escatológica da Bíblia, que veio superar os limites da simetria da justiça humana e instaurar um tempo linear, o tempo da História e da escatologia rompendo com a tradição moral e jurídica da Antiguidade pagã. No entanto, o que permitiu dar cumprimento àquele programa bíblico do agir sobre a história foi a nova visão do mundo, forjada durante a Idade Média europeia, entre o século XI e o século XIII, que é normalmente designada por "Reforma Gregoriana" mas que Philippe Nemo, aliás com Harold J. Berman, prefere designar como "Revolução Papal" e que é também considerada um dos cinco factores do Ocidente. Nesta ordem de ideias, a "Revolução Papal", que acompanhou os séculos XI a XIII, consistiu em utilizar a razão humana, nas duas formas da ciência grega e do direito romano, para integrar a ética e a escatologia bíblicas na história, realizando assim a primeira verdadeira síntese entre Atenas, Roma e Jerusalém.

Finalmente, como factor derradeiro, responsável pelo rosto moderno da Europa, Philippe Nemo enuncia a promoção das instituições democráticas nos países ocidentais modernos e, com elas, do pluralismo crítico (na vida intelectual, científica e social, na política e na economia), pluralismo crítico que, sem se confundir com o cepticismo ou o relativismo, mas antes aceitando o carácter essencialmente falível da razão humana, deu ao Ocidente uma capacidade de desenvolvimento sem precedentes e permitiu-lhe gerar a modernidade ${ }^{4}$. A seiva que atravessa este organismo vivo, desde a origem, mesmo quando se trata do rosto moderno da Europa, é, porém, grega.

${ }^{4}$ Entre as instituições que permitiram a emergência do mundo moderno, inscreve-se a democracia representativa, o sufrágio universal, individual, livre e secreto, a separação de poderes, a independência da justiça, a administração neutra, os mecanismo de protecção dos direitos do homem, a liberdade religiosa, a liberdade de investigação científica, as liberdades académicas, a liberdade de educação, a liberdade de imprensa, a livre iniciativa e a liberdade do trabalho, a protecção da propriedade privada, material ou imaterial, e o respeito pelos contratos. 
Todos estes valores e instituições são fruto de uma longa construção histórica que não é patrimónịio de um povo mas de povos diversos que tomaram para si, voluntariamente, valores estranhos ao seu grupo de origem. Na verdade, não foram só os romanos que se helenizaram; os povos vencidos da Europa pagã assimilaram a latinidade e converteram-se, em massa, ao cristianismo. Depois, foi a Europa cristã que se apropriou do saber grego e do direito romano, ambos pagãos, e fez daqueles patrimónios passado do seu passado, fonte da sua identidade. Os diversos grupos foram assumindo retrospectivamente uma paternidade espiritual que nem sempre correspondia à sua paternidade biológica. Nós mesmos, Europeus do século XXI, sabemo-nos herdeiros não apenas de Sócrates e de Aristóteles, de Cícero e de Séneca mas também (como negá-lo?) de Moisés e de Jesus Cristo.

No entanto, a relação entre a Europa e o Cristianismo, durante tantos séculos considerada evidente ${ }^{5}$, tem vindo a transformar-se, entre alguns intelectuais europeus, em tema polémico, de resultados dogmaticamente incertos.

Do mesmo modo, as relação entre Europa / helenismo e entre Europa / latinidade são, entre académicos, desvalorizadas e, em certos meios, esvaziadas, reduzidas a ocos florilégios decorativos, ao mesmo tempo que o legado greco-romano é gradualmente suprimido dos curricula, em nome de uma cultura global. Pois será realmente Homero mais "nosso" do que dos japoneses, ou dos muçulmanos? pergunta-se. Esse património não pertencerá antes a um horizonte global muito mais vasto, em que a antiguidade "clássica" tem o seu pequeno lugar entre muitas outras "antiguidades" - indianas, chinesas, maias, celtas - todas igualmente legitimadas enquanto depósitos de nomes, historietas, citações, metáforas e curiosidades, de função ornamental? Num contexto marcadamente multicultural como o nosso, qual será a actualidade do "clássico" ocidental, quais as suas peculiaridades distintivas (se as houver) que continuam vivas e significativas ${ }^{6}$ ?

${ }^{5}$ Cf. por exemplo, B. Croce, "Perché non possiamo non dirci Cristiani" La Critica XL (1942), 289 ss. O cristianismo modelou indelevelmente o nosso modo de agir e de pensar. Essa é uma das maiores diferenças que separam o espírito europeu do espírito de um cidadão de Atenas ou de Roma.

${ }^{6}$ Este e outros pontos de vista são problematizados por Salvatore Settis, Futuro del 'classico'. Turin, Einaudi, 2004. Denunciando a obsessão pelo contemporâneo, própria do nosso tempo (nomeadamente no capítulo dedicado ao conceito de clássico no universo do global), o autor sustenta que nenhuma civilização pode pensar-se a si própria se não dispuser de outras sociedades que lhe sirvam de termo de comparação, de outro lugar no tempo e de outro lugar no espaço. Por isso, quanto mais soubermos olhar para o clássico não como ruínas ou como herança morta mas como algo vivo que é preciso redescobrir no diverso, tanto mais seremos capazes de formar as gerações futuras. 
É evidente que os acontecimentos que criaram a cultura ocidental ao longo da história pertencem ao mundo das ideias, das doutrinas, das representações, das realidades propriamente culturais, pelo que não constituem propriedade exclusiva de ninguém. Podem efectivamente ser apropriados por todos os povos do mundo. Mas a verdade é que é justamente o Ocidente, a que pertencemos, que é fruto de cada um destes fenómenos chave da sua história, e nenhum deles pode ignorar a participação do outro na construção do património espiritual e cultural milenar em que vivemos - pois seríamos como arquitectos a duvidar do "contributo do betão armado para construção do vão da ponte da Arrábida"". Por muito global que seja a cultura em que vivemos, a atitude do jovem estudante europeu face à história de Roma ou da Grécia não poderá ser certamente a mesma do chinês, ou do muçulmano.

Falso também seria arquitectar a morfogénese do Ocidente cultural sobrevalorizando o seu passado ancestral (greco-romano e judaico-cristão) e amputando-a dos progressos civilizacionais que criaram o rosto moderno da Europa. A reforma cluniacense do século $\mathrm{X}$, e a reforma gregoriana (o Dictatus Papae de 1074-1075, de Gregório VII), os grandes concílios ecuménicos, convocados pelos papas para organizar a sociedade cristã (os quatro concílios de Latrão em 1123, 1139, 1179 e 1215 e o concílio de Lião, em 1245), foram fenómenos cujos efeitos se estenderam das estruturas da igreja à sociedade civil, reorganizando o conhecimento, os valores, as leis e as instituições da sociedade europeia, no seu conjunto. A criação de uma nova legislação canónica universal, emanada dos concílios, a superação dos direitos bárbaros locais e a síntese operada entre o direito romano e a moral cristã, fizeram com que o suposto código de honra que autorizava os ciclos de vinganças fosse dando lugar às normas disciplinadoras da violência na sociedade. Desta reorganização resultou, para o Ocidente, a efectiva separação entre o poder espiritual e o poder político. Nascia por um lado, o Estado de Direito, de significado essencial para a Europa. Por outro lado o incremento da escola, desde a renascença carolingea, e a criação das primeiras universidades europeias, dava às artes liberais, elaboradas pelo mundo greco-romano e sempre mantidas, aliás, nas escolas monásticas e episcopais, um novo estatuto de autonomia e de vitalidade. Em todos os saberes, mas particularmente na filosofia, iam-se consolidando os métodos aristotélicos mais racionais. Era a visão científica grega do homem e do mundo, operada por Aristóteles, que dava corpo à síntese cristã da nova cristandade. Era o método aristotélico que estava por detrás do pensa-

${ }^{7}$ A imagem é de J.C. de Miranda em "Identidade europeia: Utopia ou Paraíso perdido" Cenáculo 43.170 (2004) 7-34. 
mento sistemático de Pedro Lombardo e da Suma Teológica de São Tomás, que era elaborada num plano essencialmente ordenado e racional. Razão científica e natureza humana são agora colocadas ao serviço do ideal ético Bíblico.

Foi por esse caminho, e não outro ${ }^{8}$, que os povos cristãos da Europa medieval integraram plenamente, na sua identidade, a herança racional científica e humanística da Antiguidade greco-latina. Somos, desde então, uma respublica litteraria, respublica ciuilis e respublica christiana ou seja, uma síntese de Atenas, Roma e Jerusalém.

\section{A RATIO STUDIORUM}

Feita esta reflexão, é meu intento salientar agora o contributo de um documento do século XVI, a Ratio Studiorum da Companhia de Jesus (de 1599) para a construção da identidade europeia, tal como acima ficou descrita.

A Ratio Studiorum foi como se sabe, o regime de estudos (curriculum e regulamento escolar) que presidiu a todos os colégios dos Jesuítas, quando estes criaram aquela que foi a primeira rede escolar de dimensão verdadeiramente europeia.

Numa Europa em mudança acelerada (de uma cultura essencialmente oral para uma cultura em que a prática da escrita ascende a um lugar de importância extraordinária, em que a procura da escolarização cresce de forma maciça, sem que as instâncias civis e políticas possam responder às necessidades sociais), cada colégio era não apenas parte de uma vasta rede de instituições escolares que deslocava docentes e discentes em toda a Europa ${ }^{9}$, mas também um verdadeiro centro de cultura, com repercussões crescentes na vida das cidades, lugar de realização de espectáculos, teatros, bailados e mais tarde de óperas; espaço para a criação de bibliotecas, oficina para a impressão de novos livros, alfobre de laboratórios, de museus naturais e de observatórios astronómicos ${ }^{10}$.

${ }^{8}$ Não é demais sublinhar, como Philippe Nemo (O que é o Ocidente... p. 79 ss.), a importância do ideal ético bíblico como aguilhão do conhecimento e da razão humana, no programa das diversas reformas conduzidas pela Igreja. De facto, as sociedades muçulmanas, grandes depositárias do saber grego, não conheceram o mesmo desenvolvimento científico e racionalista característico das sociedades ocidentais. $\mathrm{O}$ averroísmo conheceu maior futuro no Ocidente do que no próprio Islão. "Se as causas materiais [a transmissão dos textos] tivessem bastado", escreve, "Galileu teria sido Mongol." (p. 82).

${ }^{9}$ Um professor de Retórica ou de Artes podia ser deslocado entre em Coimbra, Roma, Viena, Paris ou Colónia. O Colégio de Coimbra, por exemplo, todos os anos atraía novos alunos vindos do Norte da Europa.

${ }^{10} \mathrm{Um}$ fenómeno que caracterizou a Ordem, desde os primeiros anos da sua actividade escolar, foi, com efeito, a publicação de livros em grande escala, num esforço por recuperar 
Na medida em que o programa educativo eleito pela Ratio para transmitir às gerações foi fundado justamente sobre a sintese daqueles três legados fundamentais, a Ratio Studiorum tornou-se fiel depositária do património literário, científico, cultural e espiritual do Ocidente e soube transmiti-lo à Europa, através de uma rede de instituições escolares que antecipou uma certa experiência de democratização do ensino, ante litteram ${ }^{11}$.

$\mathrm{Na}$ medida em que os colégios de Jesuítas formaram efectivamente muitas gerações de homens, que se distinguiram em todas as partes do mundo e nos mais variados campos das ciências e das artes, os seus mestres podem ser considerados "mestres da Europa"12.

$\mathrm{Na}$ medida em que formou intelectual e cientificamente a Europa, o ensino da Ratio Studiorum colaborou ainda no advento do seu rosto moderno, formando não apenas o intelectual-cientista, votado à erudição, mas também o cidadão activo, apto a intervir na comunidade a que pertence - o homo politicus, cada vez mais inseparável do homo sapiens e do homo loquens.

\section{ATENAS, OU A ESCOLA. AS ARTES LIBERAIS E AS CIÊNCIAS NATURAIS}

A noção de escola enquanto instituição dedicada a transmitir um determinado saber à sociedade, é grega (o mundo romano mais não fez do que adoptar o modelo escolar do seu vencido). É grego o ideal de paideia, que Cícero traduz por humanitas, e que inspirou os autores da Ratio quando estes adoptaram um programa de estudos semelhante ao das escolas humanistas

as fontes greco-latinas. A Ratio reflecte essa preocupação incessante de dotar os discípulos dos mais actuais instrumentos de trabalho.

${ }^{11}$ Efectivamente, até então, a formação intelectual e os próprios studia humanitatis continuavam confinados a grupos de eruditos, príncipes e cortesãos, familias de uma certa condição social, ou eclesiásticos, ao passo que, obedecendo a uma ética humanística, os colégios são abertos aos homens de qualquer condição e constituem para muitos a oportunidade de ascender na escala social.

${ }^{12} \mathrm{Um}$ argumento a favor desta mesma ideia é a objectividade dos números. A consulta dos Catálogos da Companhia de Jesus revela o número efectivo de instituições escolares criadas pelos jesuitas na Europa, na Índia, na China, no Brasil, em África. Em poucos anos as escolas multiplicam-se, não só nas grandes cidades, mas também em cidades sem tradição de ensino universitário. Cfr "Humanismo jesuítico e identidade da Europa. Uma comunidade pedagógica europeia" Humanitas LIII (2001) 83-111; "Os Jesuitas, mestres da Europa. Mobilidade e cosmopolitismo de um corpo docente" in Latineuropa. O latim e a cultura neolatina na construção da identidade europeia. Coimbra, 2008, 225-236. O ritmo de crescimento dos colégios foi de tal ordem que a II Congregação Geral (1565) afirmou a exigência de limitar o número de colégios para consolidar esforços nos já existentes. 
italianas, ou seja um programa de estudos humanístico. É o ideal de uma humanidade que não se cumpre senão praticando as artes liberales, isto é o saber humanístico e científico.

Se um dos agentes de coesão da noção de Europa é o facto de ela ter sido espaço do nascimento e desenvolvimento do saber e das ciências, então a Companhia de Jesus, com a sua missão educativa incarnada numa rede escolar europeia e internacional, exerceu, ao longo de mais de dois séculos, um papel preponderante no processo de construção da Europa. E a Ratio Studiorum que presidiu de forma universal à sua actividade escolar, com o seu postulado sobre a aliança indissolúvel uirtus et litterae, inscreveu a acção daqueles homens no processo, inaugurado pelo Humanismo, de construção da Europa cultural moderna.

Herdeiro, sem dúvida, da tradição greco-latina do triuium e do quadriuium, o curriculum de estudos da Ratio transpunha para o ensino das sucessivas gerações europeias a diferente valorização de saberes que estava subjacente ao fenómeno do Humanismo, estabelecendo uma nova hierarquia de saberes.

Alcançando aquilo que poderíamos chamar os estudos secundários e os estudos superiores, a Ratio Studiorum colocava no centro do seu próprio edificio a retórica e a eloquência, concebida esta à imagem de Isócrates, Cícero e Quintiliano, como coroamento supremo dos estudos. Recuperava-se assim o ideal antigo da retórica não já como uma técnica, mas como integração dos saberes e princípio unificador da cultura. A formação do orador coincidia com a formação do homem completo e era inseparável da filosofia, da história, do direito e das ciências.

Se os humanistas italianos dos séculos XV e XVI foram os primeiros autores de um curriculum de estudos verdadeiramente humanístico, foram os Jesuítas os primeiros responsáveis pela respectiva divulgação à escala europeia e à escala global, num sistema de educação supranacional e supracontinental, desde o Brasil à China mais longínqua. A Ratio Studiorum representa pois a primeira forma de institucionalização de um curriculum de estudos humanísticos de alcance público, na Europa moderna. Por meio deste documento, os jesuítas institucionalizaram o ensino dos studia humanitatis, fazendo deles o distintivo da sua acção pedagógica ${ }^{13}$.

Humanidades, retórica, artes (ou filosofia) e teologia era o percurso normal do estudante, mas a designação destes ciclos de estudos não torna patentes todas as áreas do saber ministradas nos colégios.

${ }^{13}$ Vd. Margarida Miranda, «A Ratio Studiorum ou a Institucionalização dos Estudos Humanísticos» Biblos volume V (2 $2^{\mathrm{a}}$ série) (2007) 109-130. 
Se o estudo das humanidades e da retórica já era, por natureza, interdisciplinar, a tradição escolástica do estudo de Aristóteles não excluía a chamada 'filosofia natural', pelo que o estudo de matérias científicas, como a biologia, a física ou a astronomia e a psicologia também estava previsto pelos autores da Ratio. Na verdade, o termo humanitas pretendia traduzir a palavra grega paideia, que se referia simultaneamente à formação humana integral e ao processo que a ela conduzia. A combinação do estudo da língua e da literatura, da poesia, da história, da retórica e da lógica, com os estudos de matemática, geografia, filosofia e ciências naturais era, para humanistas e para jesuítas, não só a via para o verdadeiro desenvolvimento intelectual, mas também para o desenvolvimento moral que levava o indivíduo a agir para o bem comum.

A necessidade das artes liberais (ou intelectuais) e das ciências naturais para a prossecução dos objectivos deste curriculum está patente no capítulo IX, 1, das Regras para o Professor de filosofia.

Uma vez que as artes liberais, tal como as ciências naturais, predispõem o intelecto para a teologia, estão ao serviço do seu perfeito conhecimento e da sua aplicação prática e contribuem por si só para esse fim, o professor de filosofia deverá tratá-las com toda a diligência, procurando em tudo sinceramente a honra e a glória de Deus, de modo a preparar os seus alunos (especialmente os Nossos [jesuítas]) para a teologia $\mathrm{e}$, acima de tudo, a despertar neles o desejo de conhecerem o seu Criador ${ }^{14}$.

Porque as artes liberais e as ciências naturais predispõem o intelecto para o conhecimento da teologia, devem os mestres tratá-las com toda a diligência eis a ideia central que subjaz a todos os capitulos da Ratio. Era esse aliás, o princípio dinâmico que Philippe Nemo reconhecia ter sido, na Europa, responsável pelo "segundo começo da ciência mundial": a santificação da razão, ou seja, o intento de cumprir, na história, a ética e a escatologia bíblicas ${ }^{15}$.

O valor moral da investigação científica foi pois a razão que levou os autores da Ratio a dar o devido lugar ao estudo da matemática, da física, da astronomia, da geografia e da psicologia, como da teologia e da Sagrada Escritura.

Formatados, hoje, pela pulverização moderna dos saberes, não nos ocorre que, depois de cursar humanidades e retórica, os estudantes do segundo ano de filosofia tivessem diariamente aulas de matemática. E se alguns revelassem

${ }^{14}$ Ratio Studiorum da Companhia de Jesus (1599). Regime escolar e curriculum de estudos. Introdução, versão e notas por Margarida Miranda; Ratio Studiorum, um modelo pedagógico por José Manuel Martins Lopes S.J., Ed. Alcalá, 2008, doravante Ratio Studiorum ou simplesmente Ratio.

${ }^{15} O$ que é o Ocidente, p. 76 ss. 
maior aptidão ou interesse por aqueles estudos, teriam ainda um acompanhamento especial, com lições complementares (Ratio I. 20). O programa incluía os Elementos de Euclides e o tratado Da Esfera de João de Sacrobosco ${ }^{16}$, ou conhecimentos de geografia, como se pode ler na Ratio (capítulo XI), e esse conteúdo era objecto de discussões públicas regulares, como acontecia com as matérias filosóficas e literárias ${ }^{17}$.

Recentemente, são numerosos os estudos que demonstram o importante contributo da Companhia de Jesus para o desenvolvimento das ciências, e que provam que os Jesuítas tomaram parte não despicienda naquilo a que se chamou a revolução científica, ao nível da matemática, da física, da biologia, da química, da música, etc. Testemunhas dessa actividade são os estudos de Luce Giard (ed), Les Jésuites à la Renaissance. Systeme educatif et Production du savoir, P.U.F., 1995, maxime cap. 11; ou os estudos de Antonella Romano, nomeadamente La Contre-Reforme Mathématique. Constitution et Difusion d'une Culture Mathématique Jésuite à la Renaissance (1560-1640), Grenoble, 1999, em que a autora descreve os diversos mecanismos pelos quais a Companhia constituiu e difundiu uma cultura matemática jesuítica, estabelecendo entre Roma e as províncias um diálogo permanente sobre a dupla questão do ensino da matemática e da respectiva reflexão epistemológica; ou mais recentemente os estudos de Mordechai Feingold (ed), Jesuit Science and the Republic of Letters, Cambridge, The Mit Press, 2003 e The New Science and Jesuit Science: Seventeenth Century Perspectives, Virginia Polytecnic Institute, Blacksburg, 2003;

16 João de Sacrobosco ensinou em Paris nos anos 1220-1235 e é autor de quatro manuais importantes: Algorismus, Tractatus de Sphera (um pouco antes de 1230), Computus e Tractatus quadrantibus. Do tratado De Sphaera, estudado nas universidade europeias durante mais de quatro séculos, existe tradução inglesa: L. Thordyke - The 'Sphere' of Sacrobosco and Its Commentators. Chicago, 1949. Em Portugal, o De Sphera de Sacrobosco, além de estar presente em Alcobaça, é citado por D. João I, no Livro da montaria e também por Duarte Pacheco Pereira, no Esmeraldo de situ orbis. Cf. Pina Martins, «O Humanismo (1487-1537)» in História da Univerisdade em Portugal. I Volume, tomo I (1290-1536), Coimbra, 1997, p. 176 e A. da Costa Ramalho «O Humanismo (depois de 1537)" ibidem, tomo II, p. 701, nota 14. Devo esta nota à colaboração desinteressada do Doutor Mário Santiago Carvalho. O tratado do séc. XIII foi traduzido para português, com amplas anotações e comentários, por Pedro Nunes (Tratado da Esfera, 1537).

${ }_{17}$ Antes mesmo da promulgação da Ratio Studiorum, em 1590, no Colégio de Santo Antão, em Lisboa, havia uma classe designada Aula da Esfera, destinada ao ensino da matemática, à qual ficou associada uma tradição de bons professores. Para alguns, o colégio de Santo Antão foi, durante muito tempo, o melhor centro que houve em Portugal para o estudo das ciências, o qual contou, desde 1723 (aproximadamente), com um observatório astronómico. Baltasar Teles, Crónica, I, 81-87.; Francisco Rodrigues, História da Companhia de Jesus na Assistência de Portugal, 4 tomos, Porto, 1938-1950; I/1 281-290, I/2, 290 -302; II/1, 163-174. 
do mesmo modo, Katharine Park e Lorraine Daston (ed), ao organizarem recentemente, em 2006, The Cambridge History of Science. Vol. 3 Early Modern Science (Cambridge University Press) também não puderam ignorar a actividade científica e intelectual dos religiosos neste campo do conhecimento, o que mostra o lugar efectivo da interacção de saberes na missão educativa dos jesuítas e, por consequência, o lugar efectivo dos jesuítas na criação da Europa moderna ${ }^{18}$.

Porque o conhecimento das criaturas era o melhor caminho para o conhecimento do criador, o saber científico era parte integrante do plano de estudos da Ratio e Aristóteles, o seu objecto principal. O corpus aristotélico constitui, como não podia deixar de ser, a espinha dorsal dos estudos em Artes, agora com um novo interesse pelo estudo directo do texto do estagirita ${ }^{19}$.

A menos que algum ponto contradiga a doutrina aprovada em toda a parte pelas universidades, principalmente se se opuser à verdadeira fé, em matérias de maior importância [o professor] não se afastará de Aristóteles. (Ratio Studiorum IX, 2)

O professor esforçar-se-á com diligência por comentar bem o texto de Aristóteles, e porá nisso tanto empenho como na discussão das questões. Deve persuadir os seus discípulos de que, se não derem grande importância ao estudo dos textos, a sua filosofia será deficiente e como que mutilada. (Ratio Studiorum IX, 12)

Na opinião dos autores da Ratio, sem o conhecimento directo do texto de Aristóteles, o estudo da filosofia ficaria incompleto. Por esse motivo, o corpus

${ }^{18}$ Vd. Também, William Walace, Galileo and his Sources: the Heritage of the Collegio Romano in Galileo's Science, Princeton, 1984; Steven J. Harris, Jesuit Ideology and Jesuit Science: Scientific Activity of the Society of Jesus 1540-1773, Ph. D., Univ. of Wisconsin, 1984 e ainda "Transposing the Merton Thesis: Apostolic Spirituality and the Establishment of the Jesuit Scientific Tradition" Science in Context 3/1 (1989) 29-65. Mais recentemente, entre nós, a Revista Portuguesa de Filosofia dedicou ao mesmo tema um número monográfico com o título Os Jesuitas e a Ciência (séc. XVI-XVIII) LIV (1998). De entre os investigadores portugueses nesta matéria, distinguem-se Alfredo Dinis, da Universidade Católica (Braga), Henrique Leitão, da Universidade Nova de Lisboa e Bernardo Mota da Univ. de Lisboa.

${ }^{19} \mathrm{O}$ pensamento de Aristóteles constitui a base do pensamento filosófico de São Tomás e da chamada filosofia escolástica. Vd. a obra de A. de Libera, nomeadamente $L a$ philosophie médiévale, nouvelle édition, Paris, PUF, 2004 (A Filosofia Medieval, São Paulo, Edições Loyola, 1998); "Aristotélisme médiéval», Encyclopaedia universalis, Corpus, t. 2, Paris, 1990, p. 972-975; «Pensée médiévale», Encyclopaedia universalis, Corpus, t. 14, Paris, 1990, p. 841-853 ; Penser au Moyen Age, Nouvelle édition, Paris, Éd. du Seuil, 1996 (Pensar na Idade Média, São Paulo, 1999) e «Les Écoles et la tradition intellectuelle au Moyen âge», in Histoire de la France littéraire, Tome 1, Naissances, Renaissances, Moyen Age-XVle siècle, sous la dir. de F. Lestringant et de M. Prigent, Paris, PUF, 2006, p. 543-553. 
aristotélico é objecto de estudo desde o início e lá se encontram de forma evidente os livros da física. O primeiro ano de filosofia, embora seja dedicado à lógica $^{20}$, já inclui o segundo livro da Física e o segundo do tratado Sobre a Alma, além dos livros Da Interpretação, Primeiros Analíticos, Tópicos e Refutações Sofisticas, que constituem o ciclo da lógica (Ratio Studiorum IX, 9. 1-6).

O segundo ano de filosofia inclui os oito livros da Física, o tratado Sobre o Céu, o primeiro livro do tratado Sobre a Geração e Corrupção e ainda os Metereológicos, encerrando assim o ciclo da física (IX, 10.1-3).

O terceiro ano compreende o livro segundo do tratado Sobre a Geração e Corrupção, os livros do tratado Sobre a Alma (com relevo para tudo aquilo que, nesta obra, se refere aos órgãos dos sentidos) e a Metafisica (IX, 11.1-2). Os parágrafos seguintes (IX, 12-20) sublinham a importância do conhecimento do texto de Aristóteles e descrevem cuidadosamente o método a seguir pelo professor, quer no comentário, quer na discussão das questões.

Para os alunos de Metafísica, isto é, do terceiro ano de filosofia, o corpus aristotélico estendia-se ainda à filosofia moral e incluía os dez livros da Ética de Aristóteles, num estudo sempre orientado para o conhecimento rigoroso do texto, evitando explicitamente as divagações de carácter teológico.

E dir-se-ia que o conhecimento do corpus aristotélico terminaria aqui. Além da Retórica e da Poética, previstas para a classe de retórica, a Ratio Studiorum não faz qualquer referência aos livros de política, nem aos livros dos animais (História dos Animais, Partes dos Animais, Movimento dos Animais e Geração dos Animais), nem aos designados Parua Naturalia.

No entanto, os Commentarii Collegii Conimbricensis, criados como instrumento ao serviço do ensino da filosofia e usados em toda a Europa, constituem um outro testemunho vivo do conhecimento jesuítico do corpus aristotélico. A edição do chamado Curso conimbricense estreia-se em 1592 com o comentário aos oito livros da Física, e é logo no ano seguinte que surgem não só os comentários ao tratado Sobre o Céu, aos Livros Metereológicos e à Ética a Nicómaco, mas também aos oito livros tradicionalmente conhecidos como

${ }^{20}$ Através das obras de Francisco Toledo e de Pedro da Fonseca. Francisco Toledo (1532-1596) é o cardeal jesuíta de Córdova, conhecido pelos seus comentários a Aristóteles e à Summa de São Tomás. Pedro da Fonseca (1528-1599) é o jesuíta português autor dos Institutionum Dialecticarum Libri Octo (Coimbra, 1574) que fizeram dele um dos principais representantes da segunda escolástica e que lhe valeram o título de 'Aristóteles português' (A.M., Martins, «Fonseca (Pedro da)», in Logos - Enciclopédia Luso-Brasileira de Filosofia) Era professor no Colégio das Artes de Coimbra, quando o P. Nadal the ordenou que preparasse um curso de filosofia para imprimir, dando assim origem à ideia do célebre Curso Conimbricense, que todavia não foi escrito sob a sua direç̧ão. Vd. Monumenta Histórica Societatis Iesu, Monumenta Paedagogica IV, p. 225. 
Parua Naturalia: Commentarii Collegii Conimbricensis S.I. In Libros Aristotelis, qui PARVA NATVRALIA appellantur (Lisboa, Tipografia de Simões Lopes, 1593, 104 pp.). O título genérico agrupa um conjunto de pequenos tratados cujos títulos, por si só, já ilustram o seu conteúdo, mais ligado à psicologia e à biologia humana e animal: Sobre a sensação, Sobre a memória, Sobre o sono e a vigília, Sobre os sonhos, Sobre a predição pelos sonhos, Sobre a longevidade e a brevidade da vida, Sobre a juventude e a velhice e Sobre a respiração.

O estudo dos Parua Naturalia, ao lado dos outros títulos referidos pela Ratio, já se encontra, aliás, no programa de filosofia do Colégio das Artes de Coimbra de 1552 , e o mesmo acontece no de $1591^{21}$, ambos anteriores à edição definitiva da Ratio Studiorum.

Assim se estudavam todas as actividades da vida animal, desde as mais elementares (como o crescimento, a nutrição, a locomoção) às mais elevadas (como as actividades ligadas à sensação, à imaginação e ao intelecto), colocando assim em plena evidência a relação entre o corpo e a mente. A centralidade da filosofia natural no conjunto do corpus aristotélico não deixa pois de se manifestar no ensino jesuítico da filosofia e nas obras efectivamente eleitas para o programa de estudos.

Qualquer que fosse o curso a seguir, o programa de estudos da Ratio combinava os estudos das humanidades com os estudos científicos e filosóficos. Assim se deviam formar homens que soubessem pensar e comunicar; com elevados conhecimentos de literatura, de história, de geografia e de artes; com um profundo entendimento da matemática, da astronomia, da geografia e das ciências naturais; com desenvolvido sentido crítico, apurado pela retórica e pela filosofia; preparados para trabalhar e para intervir na sociedade, em nome do bem comum.

ROMA, OU A INVENÇÃO DO HUMANISMO

Na história espiritual e intelectual do Ocidente, Roma não foi apenas o intermediário que soube transmitir à Europa as duas inovações verdadeiras e substanciais da revelação cristã e da ciência grega. Roma teve um contributo específico. À teoria grega da natureza humana universal, cognoscível pela razão, Roma acrescenta o reconhecimento do indivíduo e a sua necessidade de subsistência plena. Reconhece a existência da pessoa humana singular, livre,

${ }^{21}$ Mário Brandão, O Colégio das Artes, vol. I, pp. 280-285. 
dotada de vida interior e irredutível ${ }^{22}$. Em certa medida, podemos afirmar que, tendo inventado o direito privado, os romanos inventaram a pessoa humana individual e criaram uma das fontes do humanismo ocidental. Por isso Cícero (De Officiis) aplicara ao ser humano a palavra personna, com que eram designadas as personagens do teatro. Tal como no teatro o actor tem que incarnar uma personagem, assim também na vida real cada homem tem um papel singular a desempenhar. E assim como a peça de teatro não teria sentido algum sem a articulação das diferentes personagens, também a República não existiria se os cidadãos deixassem de ser eles mesmos, apagando o carácter próprio de cada um.

Com a valorização da singularidade e do indivíduo, presente também na expressão artística literária e figurativa, o personalismo, formulado por Cícero e desenvolvido por Roma e pelo Ocidente cristão, foi provavelmente o aspecto que mais distinguiu o Ocidente do Oriente.

A comissão de Padres jesuítas encarregados da elaboração da Ratio Studiorum não podia deixar de transpor para os seus próprios princípios esta visão humanista do indivíduo, subjacente, aliás, a muitos aspectos da pedagogia inaciana e também da filosofia educacional que fizeram da Ratio um modelo pedagógico. Limitar-me-ei a apontar como o programa de estudos da Ratio é herdeiro de um certo modelo de cidadão, de origens romanas e de características modernas.

Entre as disciplinas fundamentais da Ratio Studiorum, ocupavam lugar de grande relevo a história, a filosofia moral e sobretudo a eloquência, pois todas pertenciam à ciência civil (civilis scientia). Ora, o modelo incontestável de combinação da eloquência com a actividade política era, evidentemente, a obra de Cícero e a sua teoria oratória. Esta é, aliás, a ideologia subjacente a todos os tratados humanísticos de pedagogia: os laços entre eloquência e vida política, a importância do novo curriculum emergente para o desenvolvimento da cultura, para a formação do carácter e a preparação para a vida cívica. Uma nova cultura era inaugurada, em que o homo sapiens se tornava indissociável do homo loquens e do homo politicus ${ }^{23}$.

${ }^{22}$ É evidente que, no desenvolvimento desta ideia de humanismo, o cristianismo teve um papel fundamental. No entanto, o cristianismo nunca teria podido conferir o verdadeiro valor teológico à pessoa se não tivesse incarnado numa sociedade que já tinha valorizado o ego (Nemo, O que é o Ocidente... p. 44-46).

${ }^{23} \mathrm{~A}$ educação é questão central em toda a problemática do humanismo, e coloca-se com muito maior acuidade à figura de príncipes e governantes. Sobre os novos ideais pedagógicos e cívico-políticos dos humanistas, sobretudo no que toca à educação de príncipes, em Portugal e na Europa, veja-se a obra de Nair Castro SOARES, O Príncipe Ideal no século $X V I$ e a obra de D. Jerónimo Osório, Coimbra, Instituto Nacional de Investigação Científica, 1994, em que a autora incorpora um estudo sistemático do modelo de príncipe, desde as 
Por isso não é de estranhar que a Ratio corporize uma certa inversão na hierarquia dos saberes. O eixo de todo o edifício pedagógico é agora o ensino da eloquência, à qual é reconhecida a maior utilidade social. O ideal de eloquência preconizado pela Ratio mais não é do que o ideal de Eloquência romano, intimamente ligado ao ideal de sabedoria e assim abraçado pelo humanismo renascentista. Por isso, ao estabelecer o programa de estudos da classe de retórica, a Ratio não circunscreve aquela classe a um campo específico do saber; antes expõe o seu carácter multidisciplinar e unificador:

O programa desta classe [retórica] não pode ser determinado facilmente entre limites precisos. Ela forma o estudante para a eloquência perfeita, que compreende duas matérias fundamentais, a oratória e a poética (devendo-se dar sempre a primazia à oratória). A eloquência tem em vista não apenas a utilidade do discurso mas também a sua elegância. De modo geral, porém, pode-se dizer que ela abrange três componentes principais: os preceitos de oratória, o estilo e a erudição. (Ratio Studiorum, XVI, 1)

Em lugar de conceber a retórica como instrumento, como simples exercício escolar preparatório reservado à juventude, a Ratio concebe a retórica segundo o ideal romano do Orator, que é também o do sábio, reconhecendo assim o seu estatuto superior em relação aos saberes particulares, e fazendo dela princípio unificador da cultura.

Nesse sentido, a poesia ocupa um lugar secundário. Na Ratio Studiorum, é a prosa, nomeadamente a oratória, que parece ser mais valorizada na preparação para a vida cívica, seja secular seja religiosa. Era a retórica que inspirava a gravidade do discurso profissional dos sábios, dos magistrados, dos teólogos. Era a retórica que estava presente na elevação das disputas filosóficas, filológicas e teológicas, na investigação sobre a história, na coerência dos sermões e das obras de espiritualidade. Mas do ponto de vista de uma ordem religiosa como a Companhia de Jesus, no seio de uma cristandade fracturada pela Contra Reforma, era ao sermão, aos concílios, aos sínodos, às controvérsias doutrinais e teológicas que as virtualidades da retórica e da eloquência vinham trazer maior vigor. Não uma retórica formalista e tecnicista, mas uma retórica que integrava uma vasta cultura - filosófica, oratória, poética e histórica. Para isso, ao lado dos preceitos da arte e do estilo, buscava-se também a erudição (Ratio $\mathrm{XVI}, 1)$ como componente indissociável da retórica.

fontes da Antiguidade clássica. Da mesma autora, vd. "Humanismo e Pedagogia" Humanitas 57 (1995) 799-844 e "Cataldo e Resende: da pedagogia humanista de Quatrocentos à influência de Erasmo", in Actas do Congresso Internacional do Humanismo Português, Lisboa, 2002, 311-340.. 
Se os preceitos eram tirados da obra de Cícero e de Aristóteles e o estilo era "quase exclusivamente o de Cícero" (ex uno fere Cicerone sumendus est), já a erudição se deveria colher "a partir da história, dos costumes dos povos, da autoridade dos escritores e de toda a espécie de saber..." (Ratio XVI, 1). A referência è erudição dá à noção jesuítica de retórica o sentido ciceroniano do termo, isto é, a articulação de todo o saber e de toda a virtude na palavra a dirigir à sociedade. A retórica consiste assim na unificação da cultura, e o orator é agora o uir doctissimus sed et eloquentissimus. Uma cultura dominada pela oratória, própria da cultura intelectual moderna, parecia vir sobrepor-se à cultura dominada pela filosofia e a teologia especulativa e contemplativa, própria do pensamento escolástico dos séculos XIII e XIV.

No coração do humanismo estava a restauração, na Europa, do ideal romano de eloquência. A Ratio abraçou incondicionalmente essa causa, não sem ter que travar uma longa luta contra as adversidades que então acompanhavam os professores e o ensino daquela área do saber, tradicionalmente subestimados ${ }^{24}$.

À luz deste ideal, a figura de Cícero, orador cívico, filósofo, poeta e ao mesmo tempo político activo e com responsabilidades cívicas na Respublica, adquiriu um valor exemplar e um papel central. Misto de herói e de sábio, Cícero incarna o ideal de orador ao serviço da uita ciuilis e portanto paradigma da scientia ciuilis. A sua grandeza era fruto da sua eloquência. Por isso, ele que era, desde Castiglione, modelo para cortesãos, diplomatas, juristas e conselheiros de príncipes, torna-se também modelo para o estudante a quem se oferece a formação completa de homo sapiens, homo loquens e homo politicus, capaz de prestar o maior serviço à sociedade de que será membro.

Para assegurar a qualidade do ensino em todos os colégios, a Ratio adoptava um compêndio de Retórica por onde mestres e alunos deviam aprender os preceitos, de que fala a regra 1 para os professores de retórica (Ratio XVI, 1). Esse compêndio, divulgado à escala europeia, era da autoria de Cipriano Soares, professor no Colégio das Artes de Coimbra, e conheceu uma enorme fortuna, mesmo antes de a Ratio ter promovido o seu uso nas escolas ${ }^{25}$. Os De

${ }^{24}$ Margarida Miranda, "A Ratio Studiorum e os Estudos Humanísticos, Parte I: Defesa dos professores de Humanidades" Boletim de Estudos Clássicos 37 (2002) 105-115; Vd. também Parte II: Boletim de Estudos Clássicos 39 (2003) 59-74; Parte III: Boletim de Estudos Clássicos 45 (2006) 105-113.

${ }^{25}$ Cipriano Soares, S. I., (Ocaña 1524 - Placencia 1593). Embora espanhol de origem, o essencial da sua carreira como homem de letras decorreu em Portugal, como mestre fundador do Colégio de Santo Antão (1553) e, desde 1555, professor de retórica e Sagrada Escritura no Colégio das Artes de Coimbra, cidade em que havia dado entrada no noviciado, 
Arte Rhetorica Libri Tres ex Aristotele Quintiliano praecipue deprompti, (Conimbricae [sic] apud Ioannem Barrerium, 1562) eram parte integrante do programa das classes de humanidades e de retórica, como se pode verificar nos seguintes passos: XII, 13; XV, 29; XVII, 1-2.

Assim se formou pois a eloquência de muitas gerações de homens. Embora o seu uso não fosse obrigatório, ele era positivamente recomendado pela Ratio (XVII, 1-8) e esse facto valeu-lhe mais de duzentos anos de vigência e de actualidade. A Bibliothèque de la Compagnie de Jesus de Sommervogel, regista, em cerca de 200 anos, cerca de 150 edições da obra do mestre de Coimbra, em dezenas de cidades da Europa. Mas estudos posteriores já elevaram o número de reimpressões a pelo menos 207, em diversos pontos da Europa. A fidelidade aos clássicos dera à obra de Cipriano Soares o estatuto de texto oficial, e a Ratio assegurava-lhe uma divulgação universal. Nos finais do século XVIII, os De Arte Rhetorica já tinham servido de manual a mais de cinco milhões de estudantes, dentro e fora do âmbito da Companhia ${ }^{26}$.

A importância da palavra na pedagogia escolar dos jesuítas e o amplo espaço reservado ao seu exercício foi também a razão que esteve na origem de outra obra de dimensão europeia: o já referido Curso Conimbricense, isto é, os comentários às obras de Aristóteles, publicados para auxílio de mestres e de alunos. O propósito do projecto conimbricense era libertar mestres e alunos da ingente tarefa do ditado das lições, para o exercício do debate oral. Os frutos, porém, ultrapassaram largamente aquele benefício, pois as numerosas edições da obra em toda a Europa reflectem o magistério que efectivamente se praticava, não só em Coimbra mas nas noutras instituições escolares. Compendiar as lições era a solução para poder percorrer todos os livros indicados pelo programa e reservar o tempo necessário a um ensino que se pretendia destinado ao exercício da controvérsia, à arte da disputa, isto é, à primazia da palavra.

em 1549. A sua passagem por Portugal e a actividade docente no Colégio das Artes de Coimbra, onde se cruzaram nomes como Manuel Álvares, Pedro Perpinhão, Miguel Venegas, Pedro da Fonseca, Luís de Molina, Francisco Suárez, levaram alguns autores a considerá-lo português (Marie-Madeleine Compère, nas notas à tradução francesa da Ratio e Allan P. Farrel, nas notas à tradução inglesa). Em 1580, Cipriano Soares deixou a província portuguesa e mais tarde foi nomeado, com o P. Francisco Suárez, revisor da versão da Ratio elaborada em 1586. Assim como o manual de gramática de Manuel Álvares veio mudar definitivamente o ensino da gramática nos colégios, a Retórica de Cipriano Soares tornou-se um dos mais célebres compêndios escolares, pois ao contrário de Melanchton, Mosellanus, Georg Meier, Vaseu e Ringelberg, que secundarizavam a remissão para os textos antigos, o compêndio de Soares não afastava os estudantes dos textos dos clássicos.

${ }^{26}$ Lawrence J. Flynn - The 'De Arte Rhetorica' (1568) by Cyprian Soarez S.J., 2 parts, University of Florida, 1955. 
Na verdade, a importância atribuída pela Ratio Studiorum ao estudo directo do texto (de Aristóteles ou dos autores clássicos), ao método de ensino, à introdução das questões, à estrutura das disputas, aos diferentes papéis de cada um dos seus intervenientes, leva a crer que quer o curso de humanidades $\mathrm{e}$ de retórica quer o curso de filosofia se destinava a transmitir uma sólida formação literária e científica, com uma iniciação geral às ciências de forma enciclopédica, mas acima de tudo a preparação e desenvolvimento do entendimento, mais do que do $\operatorname{saber}^{27}$. Era necessário o domínio de todos os argumentos possíveis, não para acumular conhecimentos, mas para dispor deles no exercício da comprovação e da refutação. Não se tratava, portanto, de desenvolver um debate pelo interesse lúdico na disputa, mas pela sua utilidade para enfrentar a realidade, quer na vida forense, quer na vida missionária e religiosa, em que a controvérsia teológica se tornara o género eleito.

\section{JERUSALÉM, OU A HERANÇA JUDAICO-CRISTÃ}

"Os mestres educarão os moços que foram confiados à formação da Companhia de Jesus, de forma que eles possam ir aprendendo, juntamente com as letras, também os costumes próprios do bom cristão. Portanto, quer durante as lições (se se proporcionar a ocasião), quer fora delas, será sempre intenção do mestre dispor os ânimos juvenis para o serviço de Deus e o amor das virtudes que Lhe são gratas." (Ratio, XV, 1)

É também em exemplos como este que Philippe Nemo parece encontrar fundamento para a afirmação, supra citada, de que a ética e a escatologia bíblicas foram responsáveis por um "segundo começo da ciência mundial". $\mathrm{Na}$ verdade, a educação que se pretende na Ratio é permanentemente reorientada para o binómio designado uirtus et litterae.

A educação desenvolvida pelos jesuítas não era uma educação "neutra" como aliás, nenhuma educação o é. Uma sólida instrução literária era vista

${ }^{27}$ Exprimiu essa concepção de educação um famoso ensaista, Voltaire, aluno dos Jesuítas no Collège Louis-le-Grand (1704-1711), quando atribuiu à educação a finalidade de desenvolver mais o entendimento do que o saber, e exortando a que se tivesse o cuidado de dar à criança um guia que tivesse a cabeça bem feita, de preferência a bem cheia (Essais, I, 26). Sobre o lugar dos studia humanitatis para atingir essa meta vd. Maria Helena da Rocha Pereira, "O lugar das Humanidades na formação do homem moderno". p. 469. Ao testemunho de Voltaire, a autora acrescenta o pensamento de Heraclito: "aprender muitas coisas não ensina a ser inteligente" (Fr. 40 Diels-Kranz.). In J. A. Pinto Ribeiro (Coord.), O Homem e o Tempo. Liber amicorum para Miguel Baptista Pereira. Porto, Fundação Eng. António de Almeida, 1999, 461-470. 
como o contributo indispensável para a educação do homem de bem. A todos os professores, a Ratio torna, pois, presente que a principal finalidade dos estudos é o maior serviço de Deus, e que todos os estudos devem concorrer para esse fim, desenvolvendo no aluno todas as capacidades para o 'exercício da virtude', mas de uma virtude que se pretende instruída. Numa ética humanista, aliás, o studium, o talento e o trabalho eram a forma mais alta de dignificação humana e de acesso à uirtus, e a Ratio não esquecia esse princípio.

Essa era também a razão de ser do ofício de prefeito de estudos: in vitae probitate ac bonis artibus doctrinaque proficiant.

$\mathrm{O}$ ofício do prefeito consiste em ser instrumento geral do reitor em ordem à boa organização dos estudos e à direcção e governo das escolas, (...) de tal modo que aqueles que as frequentam progridam o mais possível em rectidão de vida, nas artes liberais e no saber, para a maior glória de Deus... (Ratio, III, 1)

A íntima união que abrangia a formação 'no saber e na virtude' teve a sua mais alta expressão na constituição das Academias. As Academias destinavam-se a reforçar a componente prática dos estudos, mas os seus membros (que seriam, os membros da Congregação Mariana e os religiosos que frequentassem o colégio) deviam "distinguir-se dos demais e dar-lhes o exemplo, na prática das virtudes cristãs, na piedade, no aplicação aos estudos e na observância da disciplina escolar" (xxv, 1-3).

Esta é, no entanto, uma pequena parte do papel que Jerusalém teve no curriculum escolar jesuítico e, nessa medida, na formação intelectual da Europa. O estudo sistemático da teologia, numa fidelidade essencial a São Tomás sem excluir a variedade dos autores, a apologia do regresso às fontes bíblicas e da recuperação do texto original mediante o estudos das três línguas (a Ratio é herdeira da tradição dos colégios trilingues) e portanto a divulgação do latim, do grego e do hebraico, a nítida separação entre as lições de filosofia e de teologia, a participação activa nos debates teológicos da Reforma católica, a renovação profunda da formação de novos clérigos nomeadamente de pregadores, a preocupação pelo cumprimento dos decretos tridentinos, todos esses objectivos se encontram omnipresentes no complexo edifício pedagógico da Ratio.

$\mathrm{Na}$ era da valorização do texto escrito, o ensino da Sagrada Escritura não poderia deixar de gozar da renovação trazida pelos humanistas à exegese bíblica, pelo sentido de recuperação dos originais. A Vulgata de São Jerónimo, tornada texto oficial da Igreja pelo Concílio de Trento, ganhava na Ratio um estatuto de autoridade incontestável. Mas isso não isentava o professor de Sagrada Escritura do dever do conhecimento profundo das línguas (do latim, do grego e do hebraico), nem o dispensava de uma formação sólida em teolo- 
gia escolástica, em todas as outras ciências e em história. Pelo contrário, o professor de Sagrada Escritura deveria ser homem de vasta cultura, bem versado, como não podia deixar de ser, na arte da eloquência ${ }^{28}$.

O professor de Hebraico, por sua vez, devia ser igualmente versado em línguas, "não só em grego, por causa do Novo Testamento e da versão dos Setenta Intérpretes, mas também em caldaico e em siríaco, uma vez que, nos livros canónicos, são numerosas as passagens escritas nessas línguas" (i, 7). ${ }^{29}$ O seu ensino devia consistir no estudo do texto sagrado, dos vocábulos e expressões concretas e da gramática, sempre tendo em vista a defesa da versão latina de São Jerónimo. Por isso, um dos objectivos do curso de hebraico era justamente atenuar a estranheza da língua $(\mathrm{VI}, 5$ : “. $\ldots$ procure o professor agir de tal maneira que, com a sua arte, consiga atenuar a estranheza e aspereza que alguns encontram no estudo desta língua"). ${ }^{30}$

A autoridade máxima era, como se disse, o texto da Vulgata (v, 1). Captar o verdadeiro sentido das Escrituras levava o professor a analisar o texto e a buscar o seu sentido, palavra a palavra e no seu contexto mais linguístico; a recuperar a tradição dos Santos Padres $(v, 7)$ e a moderar as explicações alegóricas e morais $(\mathrm{v}, 15)$. Os originais gregos e hebraicos eram, pois, um auxílio para a maior clareza e compreensão de determinado passo. Outras versões ("as traduções latinas mais recentes, ou ainda a tradução caldaica ${ }^{31}$ e a Siríaca, ou a tradução de Teodocião, de Áquila e de Símaco", por exemplo ${ }^{32}$ ) e até mesmo

${ }^{28}$ Ratio, I, 5: "Caberá ao provincial promover com o maior zelo o estudo da Sagrada Escritura. Fá-lo-á se, para esse fim, destinar homens que sejam não só versados em línguas (o que efectivamente se reveste da maior necessidade) mas também em teologia escolástica, em todas as outras ciências e em história - homens de vasta cultura e, tanto quanto possível, bem versados na arte da eloquência".

${ }_{29}$ Setenta Intérpretes, ou simplesmente Setenta é o nome dado à tradução grega da Bíblia hebraica, feita no Egipto entre o século III e II a.C.. Língua caldaica era a designação antiga para o aramaico bíblico e a literatura judaica. A Ratio continua a usar o termo.

${ }^{30}$ A comprovar a importância dada ao texto bíblico no programa jesuítico está ainda o facto de, em 1832, a Ratio ter recomendado também o conhecimento do árabe e do sânscrito para o Estudo da Sagrada escritura

${ }^{31}$ Caldeu ou caldaico é o nome (equívoco) para designar o aramaico, a língua semítica vernacular usada na Palestina no tempo de Cristo, e usada também em alguns livros do Antigo Testamento. A designação, adoptada pelos autores antigos, segue a tradição de S. Jerónimo, mas actualmente caiu em desuso.

${ }^{32}$ A Bíblia dos Setenta, a tradução de Teodocião, a de Áquila e a de Símaco são traduções do Antigo Testamento para grego, destinadas aos judeus da diáspora, que já não sabiam aramaico. A primeira, chamada dos Setenta porque, segundo a lenda, foi feita em 72 dias por 72 judeus, gozou de grande prestígio e aceitação desde o início da História da Igreja. As outras três nasceram no século II d.C. entre judeus e para judeus, como revisão do texto 
os escritos rabínicos, seriam aconselháveis na medida em que favorecessem a versão latina da Vulgata $(\mathrm{V}, 2-5,9)$.

O curso de Teologia tinha a duração de quatro anos, e estava estruturado de acordo com a obra de São Tomás, o mestre por excelência (VII, 1-7), mas isso não suprimia a pluralidade e a necessidade de discussão (VII 2-5).

No entanto, não é apenas o peso da doutrina cristã e dos estudos teológicos na Ratio que manifesta o carácter religioso da actividade educativa da Companhia de Jesus (I,1: ut inde ad Conditoris ac Redemptoris nostri cognitionem atque amorem excitentur). De facto, a Ratio só pode ser globalmente compreendida no quadro de "uma filosofia e de uma antropologia de raízes cristãs, bem como uma concepção espiritual da vida e do próprio processo educativo". ${ }^{33}$

A intervenção da igreja pós-tridentina no campo da instrução encontrou nos Jesuitas os seus mais poderosos aliados. Bem cedo eles mostraram saber sustentar o peso organizativo de um sector até então abandonado à espontaneidade e às iniciativas locais. A notável capacidade de resposta da acção dos jesuítas à expansão da Reforma protestante resulta certamente do interesse pela questão pedagógica enquanto tal, e esta, por sua vez, resulta da plena consciência que então tinham de participarem, ao mais alto nível, numa enérgica luta ideológica, que havia dividido a própria cristandade, a luta contra a heresia. Ao invés da tradição, a nova Ordem já não se apresentava como Ordem monástica e contemplativa, mas como uma milícia pronta a participar no terreno onde se travavam os combates religiosos. A sua arma principal não era a espada nem a pólvora mas a palavra e a persuasão. Por isso, o domínio da linguagem representava um poder efectivo. A educação para a disputatio e a concertatio, o debate sistemático, a diatribe, a controvérsia é assim tão importante entre protestantes como entre católicos, sobretudo devido à acção pedagógica dos jesuítas, que exercitaram por todos os meios modernos o conhecimento dos recursos argumentativos da linguagem como preparação profissional.

Destinados à difusão da verdade católica, os jesuítas tinham consciência de que quem não possuísse o domínio da palavra seria privado de qualquer prestígio e credibilidade.

grego dos Setenta, por este ter sido seguido pelos autores do Novo Testamento. Todas estas versões circularam, no entanto, quer entre as primitivas comunidades cristãs, quer entre as comunidades judaicas de língua grega.

${ }^{33}$ Alfredo Dinis "No Quarto Centenário da Ratio Studiorum", Revista Portuguesa de Filosofia LV (1999) 217. 


\section{CONCLUSÕES}

Trinta regras, num total de 467 artigos, estabelecem as práticas internacionalmente adoptadas em relação ao governo dos colégios, ao recrutamento e formação de professores, à admissão e progressão dos alunos, às diversas fases da sua formação, ao curriculum de estudos, aos textos, aos métodos e exercícios mais habituais em cada classe, à formação religiosa e à disciplina - sempre tendo em conta a adequação aos tempos e lugares, mas sem perder de vista os objectivos que atribuíram àquele sistema pedagógico comum o mais elevado nível de exigência.

O contexto da reforma luterana e da reforma católica na Europa ilumina de forma decisiva os princípios que presidiram à criação do programa educativo da Companhia de Jesus e da Ratio Studiorum em particular. Se o objectivo de Lutero era combater a decadência moral da Igreja e recuperar o espírito originário do Cristianismo (recusando, mesmo, a instituição eclesial e a sua própria fundação, a ponto de romper com ela), as motivações da obra pedagógica dos jesuítas eram exactamente as mesmas. Ao contrário, porém, da crença luterana na sola fides, que tem sustentado o individualismo moderno, Santo Inácio conserva a convicção de que nulla salus extra Ecclesia. E o desafio protestante encontrava assim uma nova resposta, mais ampla e sistemática devido ao seu impulso missionário.

A verdade é que nunca como então foram tão evidentes os laços da Igreja com a nova cultura humanística e renascentista, agora considerada como um bem imprescindivel à própria reforma religiosa ${ }^{34}$. Em vista dos seus fins, portanto, a Companhia fazia a escolha consciente do humanismo como chave mestra do seu sistema educativo, transferindo para uma dimensão normativa agora geral, a eficácia do modus parisiensis. ${ }^{35}$

Efectivamente, um dos aspectos mais relevantes da Ratio é a atenção que presta ao método e ao mestre, em ordem à maior eficácia (magis) da aprendizagem. O mestre é sem dúvida uma das personagens chave - como aliás o próprio discípulo, na actividade incessante e sistemática a que é chamado.

Por outro lado, a hegemonia do pensamento aristotélico manifesta-se até na dinâmica dialéctica que subjaz à exposição dos problemas filosóficos, de tal maneira que os Commentarii, resume Pinharanda Gomes,

${ }^{34}$ A este propósito é extremamente significativo o livro de R. R. Bolgar (ed.), Classical Influences on European Culture A.D. 1500-1700. Cambridge, Cambridge University Press, 1976, maxime A. H. T. Levi, "Erasmus, the Early Jesuits, and the Classics", pp. 223-238.

${ }^{35}$ Codina Mir S.I., G., Aux sources de la pédagogie des Jesuites. Le modus parisiensis, Roma, I.H.S.I. 1968. 
não são expositivos de uma tese dogmática sobre cada uma dos problemas, mas sim uma enciclopédia de todas as teses sobre cada problema, teses essas expostas e demonstradas umas contra as outras (...) por forma a concluir pelo que chamariamos tese oficial. ${ }^{36}$

O mais curioso deste método consiste, na verdade, no facto de todas as teses deverem ser expostas, embora não ensinadas, isto é, não aceites nem dadas como defensáveis. As chamadas quaestiones, com a sua sequência de artigos em ordem à confutação e à refutação, com as necessáriaas objecções e argumentos, foram mesmo, no magistério dos Conimbricenses, o espaço da inovação científica, com o recurso ao contributo dos descobrimentos geográficos e cosmográficos, com autêntico interesse pelos avanços científicos, num expressão de modernidade.

Razões como estas permitiram considerar os Conimbricenses responsáveis pela

renovação dos métodos da filosofia e da teologia, recuperando espiritualidades medievais ante-renascentistas - tomismo, escotismo, realismo e nominalismo - pondo maior esmero no estilo latino por influência do gosto latino já barroquizante, corrigindo o latim bárbaro, e regressando ao latim clássico-eclesiástico. ${ }^{37}$

Classicismo, humanismo e cristianismo davam um passo importante (de uma vitalidade de pelo menos dois séculos) na configuração da Europa, na renovação do seu património cultural, científico, intelectual, filológico, literário, artístico espiritual e religioso. Integrados antiguidade clássica e cristianismo na identidade dos povos da Europa, esta ganhava um novo rosto, o rosto moderno da exaltação do homem (crente ou não crente) e da natureza humana, reconhecido este acima de tudo como sujeito, colocado acima de qualquer interesse, político, técnico-científico ou economicista. Religioso ou laico, crente ou não crente, o homem europeu é fruto desse herança.

Se um documento como a Ratio não tem de forma alguma aplicabilidade na sociedade pós-moderna a que pertencemos, no plano dos fundamentos que a sustentam ela não perdeu, porém, a sua actualidade. Assim como no século XVI Santo Inácio de Loyola aceitou o desafio protestante e acabou por impor à Europa a hegemonia do seu regime de estudos, também os educadores que nele queiram inspirar-se se deparam hoje com um novo desafio: um paradigma pedagógico essencialmente científico, secularizado tecnológico e pragmático, em que as artes e humanidades tendem a ser menorizadas para fazer brilhar as

\footnotetext{
${ }^{36}$ Pinharanda Gomes, Os Conimbricenses, Lisboa, 2005 p. 123-124

${ }^{37}$ Ibidem, 127-128.
} 
conquistas incalculáveis do progresso científico. A resposta consistirá não em voltar as costas à ciência mas em abraçá-la, vivificá-la com o sopro das artes liberales, e recuperar os valores do espírito e da pessoa - que não foram, creio, os menores produtos do Ocidente. 